\title{
Uncloaking a cryptic, threatened rail with molecular markers: origins, connectivity and demography of a recently-discovered population
}

\author{
Philippe Girard · John Y. Takekawa • \\ Steven R. Beissinger
}

Received: 3 May 2010/ Accepted: 12 August 2010/Published online: 7 September 2010

(c) The Author(s) 2010. This article is published with open access at Springerlink.com

\begin{abstract}
The threatened California Black Rail lives under dense marsh vegetation, is rarely observed, flies weakly and has a highly disjunct distribution. The largest population of rails is found in 8-10 large wetlands in San Francisco Bay (SF Bay), but a population was recently discovered in the foothills of the Sierra Nevada Mountains (Foothills), within a wetland network comprised of over 200 small marshes. Using microsatellite and mitochondrial analyses, our objectives were to determine the origins, connectivity and demography of this recently-discovered population. Analyses of individuals from the Foothills $(n=31)$, SF Bay $(n=31)$, the Imperial Valley $(n=6)$ and the East Coast $(n=3)$, combined with rigorous power evaluations, provided valuable insights into past history and current dynamics of the species in Northern California that challenge conventional wisdom about the species. The Foothills and SF Bay populations have diverged strongly from the Imperial Valley population, even more strongly than from individuals of the East Coast subspecies. The
\end{abstract}

Electronic supplementary material The online version of this article (doi:10.1007/s10592-010-0126-4) contains supplementary material, which is available to authorized users.

P. Girard · S. R. Beissinger $(\square)$

Department of Environmental Science, Policy and Management, Division of Ecosystem Sciences, University of California, 137 Mulford Hall, Berkeley, CA 94720-3114, USA e-mail: beis@berkeley.edu

P. Girard · S. R. Beissinger

Museum of Vertebrate Zoology, University of California,

Berkeley, CA 94720, USA

J. Y. Takekawa

U.S. Geological Survey, Western Ecological Research Center,

San Francisco Bay Estuary Field Station, Vallejo,

CA 94592, USA data also suggest a historical presence of the species in the Foothills. The SF Bay and Foothills populations had similar estimated effective population size over the areas sampled and appeared linked by a strongly asymmetrical migration pattern, with a greater probability of movement from the Foothills to SF Bay than vice versa. Random mating was inferred in the Foothills, but local substructure among marshes and inbreeding were detected in SF Bay, suggesting different dispersal patterns within each location. The unexpected dimensions of Black Rail demography and population structure suggested by these analyses and their potential importance for management are discussed.

Keywords California - Bird - Connectivity Cryptic species - Effective size $\cdot$ Newly discovered population . Patchy habitat - Wetland

\section{Introduction}

Discovery of a new population of a threatened species immediately raises a number of questions that are critical to conservation efforts. What is the size of the new population? Has this population gone unnoticed, or is it a recent range expansion? Where did the colonists originate? What level of connectivity exists with other populations? When the species is extremely cryptic, answers to these questions have implications that may also inform other dimensions of its life history because often little is known aside from incomplete information about range or habitat requirements, and anecdotal natural history observations.

In this paper we use genetic markers and analytical techniques to provide insights on historical and current dynamics for a previously unknown population of Black Rails (Laterallus jamaicensis) in the Sierra Nevada 
foothills (hereafter "Foothills") and make comparisons with its nearest known neighbor in San Francisco Bay ("SF Bay"). The rare, very secretive Black Rail lives under dense marsh vegetation, is rarely ever observed, flies weakly, and has a highly disjunct distribution (Fig. 1). The "new" Foothills population was discovered in 1994 near Marysville, California (CA), is isolated from SF Bay by $160 \mathrm{~km}$ and from the next nearest population in the Imperial Valley ("Southern CA") by $1100 \mathrm{~km}$ (Aigner et al. 1995; Richmond et al. 2008). It occurs in a landscape that is unusual for these rails; typically inhabiting large (>50 ha), densely-vegetated, shallow, marshes in New England, the Mid-Atlantic states, Florida, Arizona and California, Black Rails in the Foothills occur in small, irrigation-fed wetlands averaging only 1.3 ha in area (Richmond et al. 2010). The California subspecies (L. j. coturniculus) is listed as threatened by the California Department of Fish and Game (1989) due to habitat loss and degradation and to grazing (Eddleman et al. 1988; Eddleman et al. 1994). Population size of California Black Rails is thought be much larger in the wetlands of northern SF Bay (Evens et al. 1991; Evens and Nur 2002) than in the Foothills (Richmond et al. 2008).

Combining microsatellite genotyping and mitochondrial sequence analyses, we first evaluate the relationships between the Foothills population and its neighbours from SF Bay and Southern CA to elucidate its probable origins. Second, we evaluate genetic structure and current gene flow to infer the level of connectivity among rail populations. We hypothesized that these populations are highly isolated, considering the large distances between them and because Black Rails are thought to be poor dispersers, performing only very short, low flights on the rare occasions that they leave dense vegetation (Taylor 1998). Indeed, the average dispersal distance for Black Rails in the Foothills was estimated as $8 \mathrm{~km}$ from incidence function analyses (Risk et al. in press). Third, we estimate the genetic diversity, current effective sizes and demographic history of Black Rails in areas of comparable size in SF Bay and the Foothills to test the hypothesis that the SF Bay population is about 10 times larger than the Foothills population, as suggested by field studies (Evens and Nur 2002; Richmond et al. 2008), and to evaluate their respective historical declines. Fourth, we evaluate and compare local substructure and inbreeding levels in the Foothills and in SF Bay. We hypothesized that the Foothills Black Rail population may show higher inbreeding and more genetic structure than the SF Bay population because it inhabits smaller marshes which support smaller local population sizes.

\section{Materials and methods}

Study sites and sampling

We trapped rails at 18 freshwater marshes near Marysville $\left(39^{\circ} 08^{\prime} 45^{\prime \prime} \mathrm{N} ; 121^{\circ} 35^{\prime} 29^{\prime \prime} \mathrm{W}\right)$ in the Sierra Foothills within a $300 \mathrm{~km}^{2}$ area (Fig. 1d). From 1-4 birds were captured per marsh, for a total of 31 birds. In SF Bay, five large marshes ( $>100$ ha) were sampled within an area of
Fig. 1 Black Rail geographic range of the species in United States (a) and California (b) is shown as shaded areas, including a poorly known portion of the range in the Midwest indicated by a question mark based on few localities (after Sibley 2000). The sampling pattern is shown for SF Bay (c) and the Foothills (d). Letters in (c) refer to Gambonini Marsh (A), Petaluma Marsh (B), Black John Slough (C), Fagan Slough (D) and Rush Ranch (E) Letters in (d) refer to sections $\mathrm{A}, \mathrm{B}$ and $\mathrm{C}$ mentioned in the Results

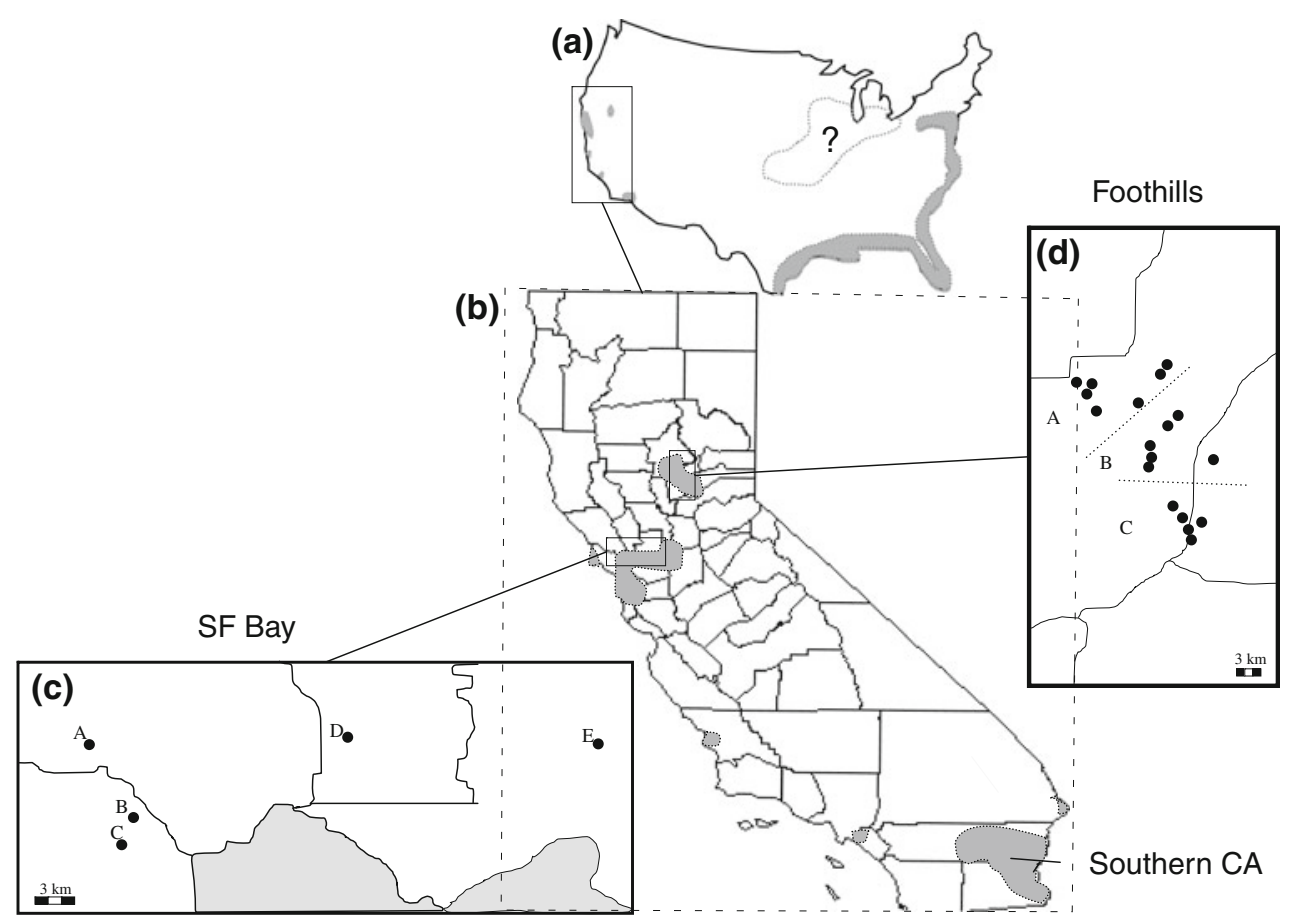


approximately $300 \mathrm{~km}^{2}$, and are representative of the remaining Black Rail habitat in the region. A total of 31 birds were captured within Black John Slough (9 birds), Petaluma Marsh (8), Gambonini Marsh (4), Fagan Slough (5) and Rush Ranch (5). To enhance understanding of Black Rail connectivity and regional isolation across California, 6 Black Rails from marshes along the All American Canal in Southern CA were also trapped. Finally, three Black Rails tissues (\#B892, B31202 and B49136) of the eastern subspecies (L.j. jamaicensis) from Florida and Louisiana were obtained from the Museum of Natural Science of Louisiana State University (LSU) and analysed as outgroups.

Capture techniques used both the night-lighting approach described in Tsao et al. (2009) and mist-netting during the day, using playbacks to lure rails to walk into the net and a drag rope to drive rails into the net if they had stopped a few feet away. The latter approach was very effective in sites with medium and high vegetation, while the former method was most effective in sites with low vegetation. Blood samples were collected from each bird by venipuncture from a superficial wing vein. Birds were banded with standard U.S. Geological Survey stainless steel bands and released. DNA from both blood samples and LSU tissues was extracted using a classic phenolchloroform protocol (Sambrook et al. 1989).

\section{Molecular analyses}

Mitochondrial DNA (mtDNA) analyses focussed on the control region (CR) because it is expected to display useful polymorphisms within species (Wenink et al. 1993; Wenink et al. 1994). Primers were first designed based on conserved sequences among different bird mtDNA genomes available on Genebank. Amplification products resulting from these primers were sequenced and primers specific to the Black Rail targeting two CR parts were designed. Part II, a 243 bp segment was located in the second third of the Black Rail $\mathrm{CR}$, and was amplified with $5^{\prime}$-CCCTAACACAACTTGC TC- $3^{\prime}$ and $5^{\prime}$-TTTTACGAAGTCCACCGG-3'. The second segment, Part III, was approximately $700 \mathrm{bp}$ long and was located within the last third (at the $3^{\prime}$ end) of the CR. It was amplified with $5^{\prime}$-TAAGTATCCGGGGAATCATC- $3^{\prime}$ and 5'-CCATCTTAACATCTTCAG-3'. The following reaction conditions were used for both pairs of primers: a $12.5 \mu \mathrm{L}$ reaction aliquot contained $3 \mathrm{mM}$ of $\mathrm{MgCl}_{2}, 2.5 \mathrm{nM}$ of each dNTP, 0.2 unit of Taq polymerase, $1.25 \mu$ of $10 \times$ Taq polymerase buffer (Invitrogen), and approximately $20 \mathrm{ng}$ of DNA. Amplification procedure included an initial denaturation of $30 \mathrm{~s}$ at $92^{\circ} \mathrm{C}$, followed by 40 cycles combining $10 \mathrm{~s}$ at $92^{\circ} \mathrm{C}, 15 \mathrm{~s}$ at $54^{\circ} \mathrm{C}$ and $10 \mathrm{~s}$ at $68^{\circ} \mathrm{C}$, and a final extension of $2 \mathrm{~m}$ at $68^{\circ} \mathrm{C}$. Sequencing was performed using an $\mathrm{ABI}$ 3730 automated DNA sequencer. Both strands of Part II were sequenced. However, the presence of a thymine mononucleotide repeat sequence close to the $3^{\prime}$ end of this segment resulted in poor quality sequences when performed with the original reverse primer. Thus, an internal primer (5'-AAAAGGAACCAGCTGCAC-3') was designed and used instead to sequence this segment in this direction. Part III was sequenced only from $5^{\prime}$ to $3^{\prime}$, resulting in sequences of $365 \mathrm{bp}$. Sequences were combined into a $608 \mathrm{bp}$ segment and a minimum spanning network was inferred using TCS v1.21 (Clement et al. 2000).

Individuals were also genotyped with the 19 microsatellite loci described in Molecular Ecology Resources primer development consortium et al. (2009). PCR products were labelled using HEX or FAM (Applied Biosystems, Inc.). Amplification products were separated on the ABI 3730 DNA sequencer and sized relative to GeneScan 500 LIZ size standard (Applied Biosystems, Inc., Foster City, CA USA). Data were analyzed using GeneMapper 4.0.

\section{Data analyses}

\section{Genetic diversity and population differentiation}

Genetic diversity within populations was calculated using gene diversity $\left(H_{\mathrm{E}}\right)$, the average number of alleles per loci, the number of mtDNA haplotypes, and their nucleotide diversity $(\pi)$. To quantify the level of divergence among the SF Bay, Foothills and Southern CA populations, pairwise genetic distances were computed and tested using ARLEQUIN v.3.1.1 (Excoffier et al. 2005). Genetic distances included $F_{S T}$ using both mtDNA and microsatellite data, and the net number of nucleotide differences (Nei and Li 1979) among mtDNA haplotypes. Significance was determined with 999 permutations.

\section{Inference of the connectivity level among populations}

Individuals were first clustered based on their microsatellites composition using the algorithm implemented in STRUCTURE v2.3.1 (Pritchard et al. 2000). Parameters were set to default values (Pritchard and Wen 2009) using the admixture model with the correlated allele frequencies option. The degree of admixture among groups $(\alpha)$ was inferred from the data and the distribution of allelic frequencies $(\lambda)$ was set to 1 . For $K$ values varying from 2 to 6 groups, we performed 20 MCMC runs of 10,000 iterations. Each run was preceded by a burn-in period of 50,000 iterations. As advised by Faubet et al. (2007), for each $K$, the run with the highest posterior probability was selected as the best solution and then used to define the best number of groups according to the method proposed by Pritchard et al. (2000). Among runs for the selected $K$ value, convergence was assessed by comparing the estimated allele 
frequencies in each cluster between the two best runs according to their posterior probability.

To evaluate conclusions about the level of connectivity among rail populations, we estimated the probability of assignment errors made by STRUCTURE. Using EASYPOP v.1.7 (Balloux 2001), we generated ten datasets that mimicked the level of differentiation using the microsatellite dataset we obtained for Black Rails (In Supplementary materials, Table S1). Because the demographic information required to perform realistic simulations for the Southern CA population did not exist and because its assignments were unambiguous, we restricted our simulation study to two isolated populations of 160 individuals, which represented the average effective sizes of the Foothills and SF Bay populations (see Results). Genotypes evolved according to a stepwise mutation model in the absence of immigration and with a rate of $10^{-5}$ mutations per generation. The number of alleles for each locus was defined as the observed number for each microsatellite (see Table S1) minus the number of private alleles observed in Southern CA. Alleles were then randomly assigned to each population, and simulations were run until $\mathrm{F}_{\mathrm{ST}}$ approached observed levels (0.03). For each dataset, a random sample of 31 individuals was selected from each population and then run together in STRUCTURE with the same parameters we used to analyze the empirical Black Rail set, except that $\mathrm{K}$ was set to 2 groups. Errors in assignment occurred if the probability of assigning an individual to its population of origin was less than $50 \%$.

Contemporary gene flow was estimated using the bayesian inference approach implemented in BAYESASS (Wilson and Rannala 2003). To estimate the posterior probability distributions of migration rates, five independent MCMC runs of 3,000,000 steps were conducted. The first 150,000 iterations were discarded as burn-in. Delta values, which correspond to the maximum amount a parameter can be changed each iteration, were set to 0.1 for all parameters except the migration rate, for which delta was set to 0.05 . These values were selected because they resulted in acceptance rates between 40 and 60\%, which was recommend by Wilson and Rannala (2003). Samples were collected every 2000 iterations to infer the posterior probability distributions of parameters. Runs with potential convergence problems were identified using the Bayesian deviance proposed by Faubet et al. (2007) and were discarded. Convergence was finally assessed by comparing the migration rate profile between the two best runs according to their average total likelihood. To ensure that migration detected by BAYESASS was the result of true migration and not simply an artefact, we performed the analysis on five of the datasets we had simulated above with EASYPOP v.1.7 (Balloux 2001) and evaluated the level of migration detected. These values, which should have been close to 0 , were then compared to the values assessed for the real Black Rail populations.

\section{Demographic stability and population effective size}

Departure from drift/mutation equilibrium was evaluated within both the Foothills and SF Bay samples using BOTTLENECK v.1.2.02 (Cornuet and Luikart 1997). Analyses were performed using an infinite allele mutation model (IAM) and a two-phase mutation model (TPM) using proportions of single-step mutations of $0.25,0.50$, or 0.75. The temporal stability of the effective size of each population was evaluated with the Wilcoxon sign-rank test (Luikart et al. 1998). Current effective population size was finally estimated in both populations using the method based on linkage disequilibrium proposed by Waples (2006) and implemented in the software LDNe v.1.31.The lowest allele frequency to be used was set to 0.01 , and $95 \%$ confidence intervals were computed using jackknife on loci.

\section{Local substructure and current inbreeding}

The potential for spatial substructure within the SF Bay and Foothills regions was investigated using Hardy-Weinberg (HWE) and genotyping linkage equilibrium exact tests available on the web version of GENEPOP (Raymond and Rousset 1995; Rousset 2008). Inbreeding level was evaluated using both the $F_{I S}$ estimator and test available in ARLEQUIN.

\section{Results}

Mitochondrial sequence diversity

Sequencing revealed 23 polymorphic sites segregated among 19 different haplotypes (Fig. 2; GenBank accession numbers [HM036687-HM036705]). The divergence between these haplotypes ranged from 1 to 10 mutations (average 2.85). The mtDNA segment showed global gene and nucleotide diversities of 0.80 and $7.6 \times 10^{-3}$, respectively. Sequencing of East Coast tissues yielded two additional haplotypes (B31202 and B892; Fig. 2); the third haplotype (B49136) had already been observed within California samples (2A). With a frequency of 0.41 and 0.18 , respectively, two sequences (1A and $2 \mathrm{~A}$ ) represented almost twothirds of the observed haplotypes. On the other hand, several haplotypes were found in single individuals $(1 \mathrm{~B}$, 1C, 1E, 2E, 1F, 2C, 2E, 2F, 2G, 2H, 2I and 3A). Haplotype $4 \mathrm{~A}$ was only found in Southern California. 
Fig. 2 Minimum spanning network based on the mutational steps of mtDNA haplotype sequences observed in Black Rails. Circle diameters reflect the haplotype frequencies among the populations surveyed. B31202 and B892 are sequences observed in individuals from Louisiana. The relative frequency of each haplotype in the Foothills (white), SF Bay (black), Southern CA (light grey) and the East Coast (dark grey) is also presented with pie charts

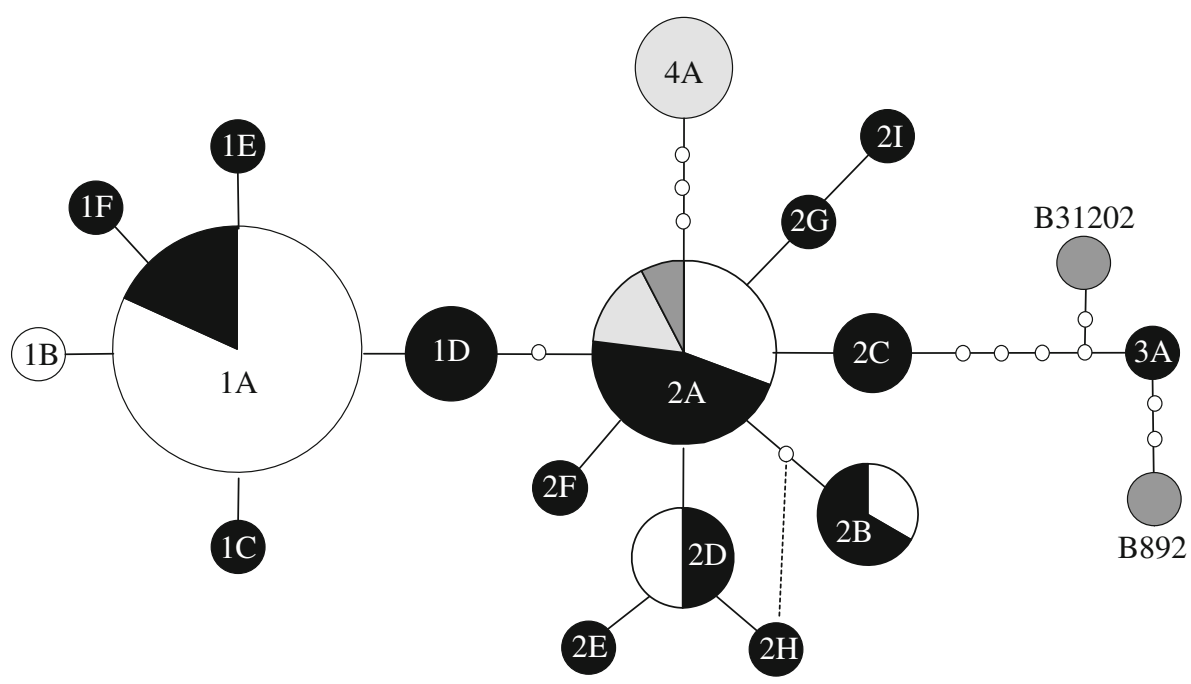

Table 1 The genetic diversity along with sample size $(n)$ of the Black rail populations analyzed in this study

\begin{tabular}{|c|c|c|c|c|c|c|}
\hline \multirow[t]{2}{*}{ Populations } & \multirow[t]{2}{*}{$n$} & \multicolumn{3}{|c|}{ mtDNA } & \multicolumn{2}{|c|}{ Microsatellites } \\
\hline & & $A$ & $H_{\mathrm{E}}$ & $\begin{array}{l}\pi \times 10^{-3} \\
( \pm \mathrm{SD})\end{array}$ & $A( \pm \mathrm{SD})$ & $H_{\mathrm{E}}( \pm \mathrm{SD})$ \\
\hline SF Bay & 31 & 11 & 0.91 & $5.1( \pm 3.0)$ & $7.9( \pm 3.2)$ & $0.74( \pm 0.14)$ \\
\hline Foothills & 31 & 6 & 0.53 & $2.6( \pm 1.9)$ & $6.4( \pm 2.6)$ & $0.70( \pm 0.17)$ \\
\hline $\begin{array}{l}\text { Southern } \\
\text { CA }\end{array}$ & 6 & 2 & 0.60 & $3.9( \pm 3.0)$ & $3.5( \pm 1.7)$ & $0.63( \pm 0.27)$ \\
\hline
\end{tabular}

For mtDNA, the number of haplotypes $(A)$, and both gene $\left(H_{\mathrm{E}}\right)$ and nucleotide $(\pi)$ diversities are presented. For microsatellites, the average number of alleles $(A)$ and $H_{\mathrm{E}}$ are shown

Genetic diversity and population differentiation

SF Bay was the most genetically diverse region in terms of the number of haplotypes (11), number of private haplotypes (6), and gene $(0.91)$ and nucleotide $\left(5.1 \times 10^{-3}\right)$ diversity (Table 1). In comparison, the Foothills samples revealed six haplotypes but only one private haplotype (1B), a gene diversity of 0.53 , and a nucleotide diversity of $2.6 \times 10^{-3}$ (Table 1) The SF Bay sample also had higher diversity average across microsatellite loci than the Foothills, both in terms of heterozygosity and average allelic richness (Table 1). However, these differences were not significant. See Table S1, Supplementary materials, for diversity information of each microsatellite.

The Foothills and SF Bay populations shared many of the same haplotypes (Fig. 2) and microsatellite alleles (75\% of the alleles observed in northern California), but frequencies differed. However, differences were more pronounced between the northern populations and the small sample from Southern California, where the highly divergent haplotype 4A occurred. Interestingly, several private alleles were also observed for microsatellite markers within all regions. Seven private alleles occurred in samples from the Foothills and Southern CA, while the SF Bay sample had 31 (Table S1). The fact that the number of private alleles was not correlated with sample size suggests that they are, at least partly, the result of a regional structuring rather than a sampling artefact. Microsatellite composition of Black Rails from the East Coast was surprisingly similar to individuals from California; only 9 out of 72 alleles observed among the three East Coast birds were not observed in the West Coast samples.

Differentiation among California populations was also indicated by significant pairwise $F_{S T}$ values computed with haplotypes frequencies (Foothills vs. SF Bay $=0.19$; Foothills vs. Southern $\mathrm{CA}=0.63$; $\mathrm{SF}$ Bay vs. Southern $\mathrm{CA}=$ 0.33 ), net haplotype differences (Foothills vs. SF Bay $=0.50$; Foothills vs. Southern $\mathrm{CA}=2.85$; SF Bay vs. Southern $\mathrm{CA}=1.50)$, and microsatellite frequencies $\left(F_{S T}\right.$ : Foothills vs. $\mathrm{SF}$ Bay $=0.03$; Foothills vs. Southern CA $=0.10$; SF Bay vs. Southern $C A=0.07)$. All of these values were significant at $p<0.01$ after Bonferroni corrections.

\section{Connectivity among populations}

Strong isolation among rail populations was apparent from STRUCTURE. A solution of three groups was clearly indicated based on its posterior probability (Fig. 3a). The best run for this $K$ value showed a clear relationship with capture location (Fig. 3b), and most individuals within a population had similar genetic composition. However, isolation was not complete, as indicated by three and four birds from the Foothills and SF Bay, respectively, that were assigned to the other cluster (Fig. 3b). Such a result was not observed for Southern California individuals, which formed a uniform and distinct cluster. These analyses reached convergence, as indicated by the strong correlation between allele frequencies estimated in each cluster among the two best runs when $K=3$ groups $(r=0.99$; 
(a)

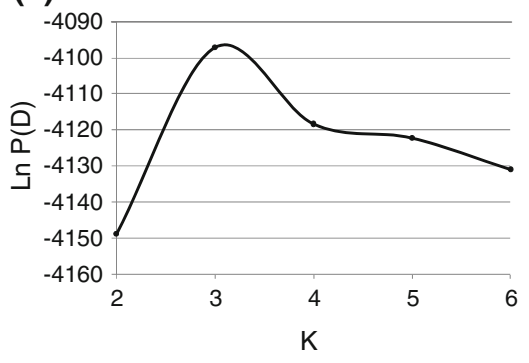

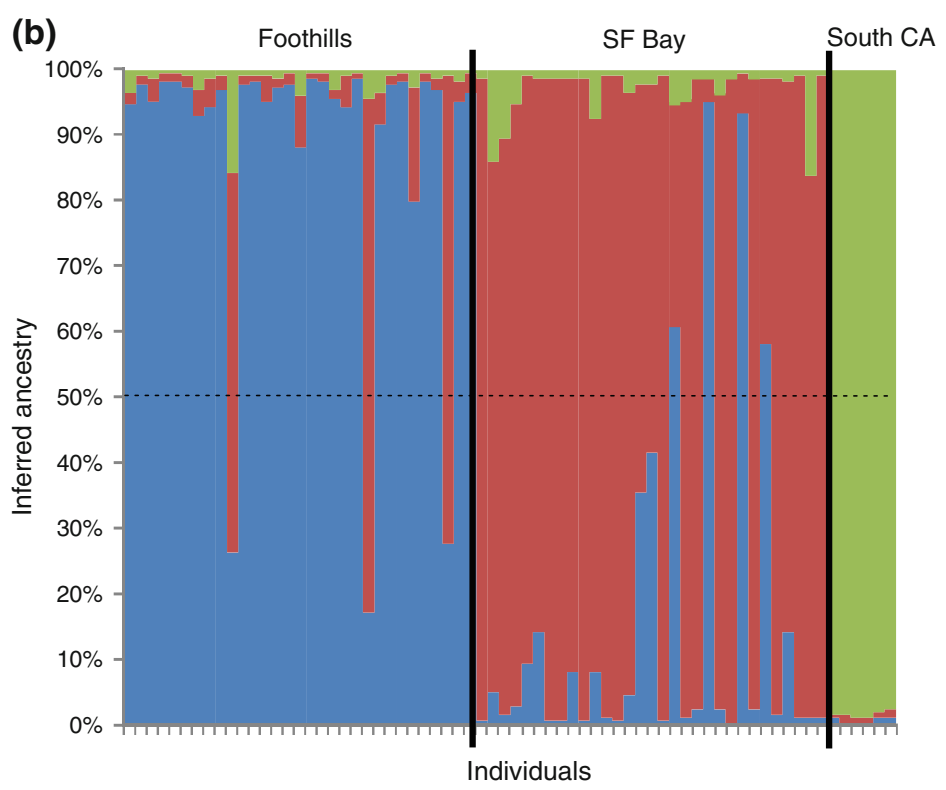

groups. Individuals are ordered on the $X$-axis according to their sampling location. For each individual, the probability of belonging to any of the three groups is presented

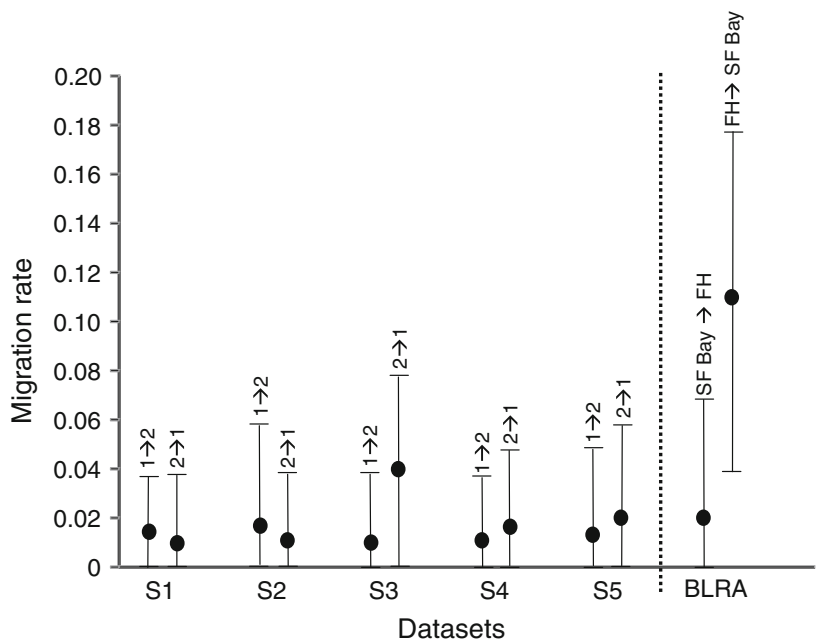

Fig. 4 The migration rate (average and 95\% confidence interval) assessed in both directions by BAYESASS for five simulated datasets (S1 to S5) representing two isolated populations (1 and 2). These results are presented along with the migration rate estimations between SF Bay and Foothills (FH) Black rail populations (BLRA)

that they had experienced a bottleneck, due to either a population crash or a founder effect. The Foothills population was not under mutation-drift equilibrium, based on the analysis implemented in BOTTLENECK. It contained a higher diversity than expected according to IAM ( $p<$ $0.001)$ and TPM with $25 \%(p<0.01), 50 \%(p<0.01)$ or $75 \%(p<0.05)$ of single step mutations, suggesting a strong bottleneck effect. For the SF Bay population, size reduction 
was also inferred from IAM ( $p<0.01)$ and TPM with $25 \%$ of single step mutations $(p<0.05)$. However, the bottleneck signal was less pronounced in SF Bay, as the single step ratio was increasing based on the results obtained with $50 \%(p=0.06)$ and $75 \%(p=0.08)$ of single step mutations. This result may suggest either a lesser bottleneck effect or an older one in SF Bay compared to the Foothills population.

Effective population sizes of the SF Bay and Foothills populations appeared comparable. Using LDNe, the area sampled in SF Bay supported a population of approximately 141 (95\% CI: 88.1-319.0) effective individuals compared to 192 birds (95\% CI: 95.3-infinite) for the Foothills. The wide and quite uninformative confidence intervals for the Foothills population suggest that our sample sizes are too small to estimate effective sizes. Furthermore, the populations were not completely closed to migration, which violates an assumption of this analysis. Thus, these results should be interpreted with caution.

Local substructure and inbreeding

Genetic structure and inbreeding analyses within each area revealed unexpected results. While we hypothesized that genetic structure should be apparent in the Foothills due to the smaller sizes of the marshes, significant substructure was not suggested from HWE $\left(\chi^{2}=34.9, p=0.6\right)$. Furthermore, linkage disequilibrium was not observed between any pair of loci after Bonferroni correction. However, substructure was suggested within SF Bay rails, as indicated by the HWE test $\left(\chi^{2}=\right.$ inf; df $\left.=38, p<0.001\right)$ and the presence of two loci pairs in strong linkage disequilibrium $(p<0.001)$. Although we acknowledge that sample sizes are limited, HWE occurred within each single marsh. Inbreeding was not apparent in the Foothills ( $F_{\mathrm{IS}}=-0.0046 ; p=0.96$ ) but was marginally significant and positive in SF Bay $\left(F_{\text {IS }}=0.044 ; p=0.054\right)$.

Whereas random mating was suggested by genotypic frequencies in the Foothills, the discordance with HWE among SF Bay marshes and their slight inbreeding level suggests substructure. These results may be driven by the sampling performed in each location. While Black Rails were uniformly sampled across the Foothills, clusters of individuals were sampled in SF Bay, which increases the probability that they are related and genetically similar. To control for this potential bias, we sub-sampled individuals from each region to mimic the distribution found in the other one. In SF Bay, we considered only the 17 individuals from the Black John Slough (9 birds) and the Petaluma Marsh (8), which are $2 \mathrm{~km}$ apart (Fig. 1c). In the Foothills, we spatially clustered the individuals in three sections (A, $\mathrm{B}$ and $\mathrm{C}$; Fig. 1d) and tested the HWE after removing section $\mathrm{B}$, leaving a sample of 19 individuals belonging to two spatial clusters approximately $30 \mathrm{~km}$ apart. In both cases, the HWE result obtained from the original dataset remained. HWE was not respected among the Black John Slough and the Petaluma Marsh in SF Bay despite their proximity, whereas HWE in the Foothills was respected among sections $\mathrm{A}$ and $\mathrm{C}$ despite representing geographical clusters of individuals distant from each other.

\section{Discussion}

Origins of the Foothills population and phylogeography of the California Black Rail

Our results strongly show the phylogeographic proximity between the Foothills and SF Bay populations, as indicated by their similar mtDNA and microsatellite compositions. However, the historical decline that both populations have suffered made more detailed phylogeographic inferences difficult. The Foothills population could have originated from colonizations by SF Bay individuals, both populations could be relicts of a population that was once more widely distributed, or both could have been colonized by a third, but now extinguished, population. Because of the mainly southern and coastal distribution of the species, it seems unlikely that the SF Bay was colonized by individuals from the Foothills. Violations of the mutation-drift and potentially of the migration-drift equilibriums also hinder a precise estimation of the time of origination for the Foothills population. However, the strong regional structure we observed may imply that the Foothills population has probably had reduced migrant exchange with SF Bay for several generations. The moderately high level of genetic diversity observed in the Foothills also suggests that this rail population has been and might still be large. It also suggests that Black Rails occurred historically in the Foothills but had gone unnoticed until the end of the 20th century (Aigner et al. 1995; Richmond et al. 2008).

The Black Rail population along the All American Canal (Southern CA) in the otherwise arid Imperial Valley has a unique and highly divergent genetic composition. High differentiation of both mitochondrial sequences and microsatellites alleles suggests a different origin than the northern populations and is consistent with a polyphyletic colonization of California. This situation is particularly intriguing because rail habitats were created relatively recently by leaks along the All American Canal, an irrigation system that was completed in 1942, and colonizers presumably originated from populations nearby on the Colorado River (Repking and Ohmart 1977; Evens et al. 1991; Conway and Sulzman 2007). Analyses of additional samples from the Colorado River, Central America, and elsewhere in the range will be necessary to determine the origins of these birds. 
Another unexpected result was the similar genetic composition of the Eastern and California Black Rail subspecies (Eddleman et al. 1994), a pattern that has also been observed for other rail species (Fleischer et al. 1995; Nusser et al. 1996). Our result is particularly striking because similarity was observed not only for mtDNA, for which the subspecies shared one haplotype, but also for several microsatellites on which most alleles were common. Although our sample sizes are small, this result suggests that a more complete phylogeographic analysis may lead to surprising conclusions, including a potential reconsideration of the taxonomic status of Black Rail subspecies.

Connectivity among populations and local sub-structure

Connectivity differed greatly among the three main California Black Rail populations. The high level of structure between Black Rails inhabiting Southern and Northern California (Fig. 3) suggests little recent exchange of individuals between the Imperial Valley and elsewhere in the state. However, recent two-way migration of individuals between SF Bay and Foothills populations is indicated by overlap between clusters and potential second generation migrants (Fig. 3). This is surprising because Black Rails are reported to be poor fliers and spend nearly all of their time walking underneath dense vegetation (Taylor 1998) and because analyses of turnover patterns using incidence function methods estimated an average dispersal distance of $8 \mathrm{~km}$ for Black Rails in the Foothills (Risk et al. in press). However, the patchy but widespread distribution of this species in North America and the partial migratory movements of the eastern subspecies (Eddleman et al. 1994) suggest that Black Rails may be more mobile than previously thought.

Estimates of migration between the Foothills and SF Bay were asymmetric, suggesting that more individuals migrate from than to the Foothills. If anything, we had expected the population in the larger marshes of San Francisco Bay to be a source of migrants to the Foothills rather than vice versa. Further investigations are needed to confirm this pattern; direct observations of rail movements have not been recorded and Black Rails are nearly absent in the Central Valley (Richmond et al. 2008). If rails engage in stepping stone migration rather than crossing the Central Valley in one large movement, the locations and characteristics of temporarily-occupied sites could be important for conservation. Conservation efforts for many threatened species, including this one, have typically targeted habitat patches used for reproduction even though other landscape structures (Cozzi et al. 2008) and dispersal corridors (Marshall et al. 2009) may play a central role in maintaining genetic diversity.
Our investigation of local substructure suggests differences in connectivity within the Foothills and SF Bay. Whereas random mating was indicated by genotypic frequencies in the Foothills, substructure in SF Bay was suggested by the discordance from HWE among marshes and the slight inbreeding level. Therefore, Black Rails may have strong site fidelity within the large, stable marshes of SF Bay as suggested by Tsao et al. (2009), whereas the absence of structure in the Foothills suggests frequent movements among the small marshes that are on average only $500 \mathrm{~m}$ apart. These results were contrary to our prediction that Foothills Black Rails should show higher levels of inbreeding and more genetic structure than SF Bay rails because they inhabit smaller marshes that support smaller local population sizes.

Population size and demographic history based on patterns of genetic diversity

The smaller size and total area of marshes in the Foothills might suggest that this Black Rail population was much smaller than the SF Bay population which inhabits larger tidal marshes (Manolis 1978; Evens et al. 1991; Evens and Nur 2002), perhaps as much as 1/10th the size (Richmond et al. 2008). Our genetic analyses, however, did not support this conjecture. Genetic diversity indices, from gene to nucleotide, computed on both the mtDNA and microsatellites markers were greater for SF Bay than the Foothills. However, these differences and differences in the estimates of effective population size were not nearly as large as expected. Although the results must be taken with caution because of our small sample sizes and violation of the assumption that the populations are closed, the similarity between genetic diversity suggest that, if anything, the SF Bay population may be smaller than initially believed, at least over the areas that we sampled. Overestimation of population size in SF Bay could occur from extrapolating density estimates derived from distance sampling at a few points to the area of the entire marsh (Evens and Nur 2002; Spautz et al. 2005) when rails likely use only a small portion, and from violations of distance sampling assumptions (Richmond et al. 2008). While our sample of Black Rails in SF Bay is limited, we did sample the largest marshes that comprise the core of this population (northern San Pablo Bay through Suisun Bay), which strengthens our conjecture that the size difference between the two populations is not as large as previously thought.

Evens (1999) argued that "because of the severe modifications imposed on shoreline habitats of San Francisco Bay over the past 150 years, it was likely that any species that was dependent on marsh habitats had suffered dramatic declines". Not surprisingly, however, there are few historic records of Black Rail presence or abundance in SF 
Bay, and no estimate of historical population levels (Spautz et al. 2005). Our preliminary genetic results suggest a slight decline in population size in SF Bay rather than a dramatic decline over the region we sampled, based on the slight departure from mutation-drift equilibrium. However, our samples come from marshes thought to contain $>90 \%$ of the extant population of Black Rails in SF Bay (Evens and Nur 2002; Spautz et al. 2005) and from a portion of the Bay that suffered less habitat loss (Goals Project 1999). There are other smaller marshes that were not sampled, as well as sites in the southern portion of SF Bay that could contain rails. Future investigations that combined genetic analyses of historic museum specimens with a wider sampling of contemporary sites may yield clearer insights into changes in rail demographic history in this region.

\section{Conclusions}

Using genetic tools we have quickly gained valuable insights into past history and current dynamics of a recently discovered population of a secretive, threatened species that would be very difficult to obtain from field study. Our results suggest that the Foothills rails represent a significant component of the range of the threatened California Black Rail, and will need careful monitoring and management. This is especially critical because a majority of Foothills sites supporting Black Rails are on private lands where they receive little protection and are fed by irrigation water that has competing uses (Richmond et al. 2010). The patterns uncovered in this work will also help to target new studies to inform unexpected dimensions of Black Rail population biology and may ultimately help prevent its extinction in the Golden State.

Acknowledgments This manuscript benefitted greatly from reviews by Laurie Hall, Per Palsboll, Zach Peery and three anonymous reviewers. We are grateful to Jerry Tecklin, Ben Risk, Orien Richmond, Elizabeth Hunt, Brandi Gartland and Laurie Hall from the Black Rail Project for their assistance on field. We also thank D. Tsao, Kyle Spragens and Brian Spirou from USGS and others acknowledged in Tsao et al. (2009) for assistance in collecting samples in San Francisco Bay. A special thanks to Tito Marchant, Joelle Fournier and Pat DelPizzo from EcoSystems Restoration Associates (ERA) for their field assistance in Southern California, and to Lydia Smith from the Museum of Vertebrate Zoology for her help in the lab. D.L. Dittmann from Lousiana State University and A. Kratter and D. Steadman from University of Florida-Gainesville provided specimens of the Eastern Black Rails. This work was supported by a FQRNT scholarship to PG, gifts from the Sierra Foothills and Sacramento Chapters of the National Audubon Society, and by SRB's funds from the A. Starker Leopold Chair of Wildlife Ecology. Any use of trade, product, or firm names in this publication is for descriptive purposes only and does not imply endorsement by the U.S. government.

Open Access This article is distributed under the terms of the Creative Commons Attribution Noncommercial License which permits any noncommercial use, distribution, and reproduction in any medium, provided the original author(s) and source are credited.

\section{References}

Aigner PA, Tecklin J, Koehler CE (1995) Probable breeding population of the Black Rail in Yuba County, California. Western Birds 26:157-160

Balloux F (2001) Easypop (version 1.7): a computer program for population genetics simulations. J Hered 92:301-302

California Department of Fish and Game (1989) California black rail, Habitat Conservation Planning Branch. California Department of Fish and Game, California

Clement M, Posada D, Crandall K (2000) TCS: a computer program to estimate gene genealogies. Mol Ecol 9:1657-1660

Conway CJ, Sulzman C (2007) Status and habitat use of the California Black Rail in the southwestern USA. Wetlands 27: 987-998

Cornuet JM, Luikart G (1997) Description and power analysis of two tests for detecting recent population bottlenecks from allele frequency data. Genetics 144:2001-2014

Cozzi G, Muller CB, Krauss J (2008) How do local habitat management and landscape structure at different spatial scales affect fritillary butterfly distribution on fragmented wetlands? Landsc Ecol 23:269-283

Eddleman WR, Knopf FL, Meanley B, Reid FA, Zembal R (1988) Conservation of North American rallids. Wilson Bull 100:458-475

Eddleman WR, Flores RE, Legare ML (1994) Black Rail (Laterallus jamaicensis). In: Poole A, Gill F (eds) The birds of North America, No. 123. The Academy of Natural Sciences, Philadelphia and The American Ornithologists' Union, Washington, DC

Evens J (1999) Mystery of the marsh: the California black rail. Tideline 19:1-3

Evens J, Nur N (2002) California Black Rails in the San Francisco Bay region: spatial and temporal variation in distribution and abundance. Bird Popul 6:1-12

Evens JG, Page GW, Laymon SA, Stallcup RW (1991) Distribution, relative abundance and status of the California Black Rail in western North America. Condor 93:952-966

Excoffier L, Laval G, Schneider S (2005) Arlequin ver. 3.0: an integrated software package for population genetics data analysis. Evol Bioinf Online 1:47-50

Faubet P, Waples RS, Gaggiotti OE (2007) Evaluating the performance of a multilocus Bayesian method for the estimation of migration rates. Mol Ecol 16:1149-1166

Fleischer RC, Fuller G, Ledig DB (1995) Genetic structure of endangered clapper rail (Rallus longirostris) populations in Southern California. Conserv Biol 9:1234-1243

Goals Project (1999) Baylands Ecosystem Habitat Goals. A report of habitat recommendations. San Francisco Bay Area Wetlands Ecosystem Goals Project. U.S. Environmental Protection Agency, San Francisco, Calif./S.F. Bay Regional Water Quality Control Board, Oakland, California

Luikart G, Allendorf FW, Cornuet JM, Sherwin WB (1998) Distortion of allele frequency distributions provides a test for recent population bottlenecks. J Hered 89:238-247

Manolis TD (1978) Status of the Black Rail in central California. Western Birds 9:151-158

Marshall JCJ, Kingsbury BA, Minchella DJ (2009) Microsatellite variation, population structure, and bottlenecks in the threatened copperbelly water snake. Conserv Genet 10:465-476

Molecular Ecology Resources primer development consortium et al (2009) Permanent genetic resources added to molecular ecology resources database 1 May 2009-31 July 2009. Mol Ecol Res 9:1460-1466

Nei M, Li WH (1979) Mathematical model for studying genetic variation in terms of restriction endonucleases. Proc Natl Acad Sci USA 76:5269-5273 
Nusser JA, Goto RM, Ledig DB, Fleischer RC, Miller MM (1996) RAPD analysis reveals low genetic variability in the endangered light-footed clapper rail. Mol Ecol 5:463-472

Pritchard JK, Wen W (2009) Documentation for STRUCTURE software: Version 2.3, available from http://www.ccg.unam. $\mathrm{mx} / \sim$ vinuesa/tlem09/docs/structure_doc.pdf

Pritchard JK, Stephens M, Donnelly P (2000) Inference of population structure using multilocus genotype data. Genetics 155:945-959

Raymond M, Rousset F (1995) GENEPOP (version 1.2): population genetics software for exact tests and ecumenicism. J Hered $86: 248-249$

Repking CF, Ohmart RD (1977) Distribution and density of Black Rail populations along the lower Colorado River. Condor 79:486-489

Richmond OM, Tecklin J, Beissinger SR (2008) Distribution of California Black Rails in the Sierra Nevada foothills. J Field Ornithol 79:381-390

Richmond OM, Chen SK, Risk BB, Tecklin J, Beissinger SR (2010) California black rails depend on irrigation-fed wetlands in the Sierra Nevada foothills. Calif Agric 64:85-93

Risk BB, de Valpine P, Beissinger SR (in press) A robust-design formulation of the incidence function model of metapopulation dynamics applied to two species of rails. Ecology

Rousset F (2008) Genepop'007: a complete reimplementation of the Genepop software for Windows and Linux. Mol Ecol Res 8:103-106

Sambrook J, Fritsch EF, Maniatis T (1989) Molecular Cloning: a laboratory manual, 2nd edn. Cold Spring Harbor Laboratory Press, New York
Sibley DA (2000) The sibley guide to birds. Knopf Publishing Group, New York

Spautz H, Nur N, Stralberg D (2005) California Black Rail (Laterallus jamaicensis coturniculus) distribution and abundance in relation to habitat and landscape features in the San Francisco Bay Estuary. In: Ralph CJ, Rich TD (eds) Bird Conservation Implementation and Integration in the Americas: Proceedings of the Third International Partners in Flight Conference. 2002 March 20-24, U.S. Dept. of Agriculture, Forest Service, Pacific Southwest Research Station, Albany, California

Taylor B (1998) Rails: a guide to the rails, crakes, gallinules and coots of the world. Yale University Press, United Kingdom

Tsao DC, Miles AK, Takekawa JW, Woo I (2009) Potential effects of mercury on threatened California Black Rails. Arch Environ Contam Toxicol 56:292-301

Waples RS (2006) A bias correction for estimates of effective population size based on linkage disequilibrium at unlinked gene loci. Conserv Genet 7:167-184

Wenink PW, Baker AJ, Tilanus MGJ (1993) Hypervariable-controlregion sequences reveal global population structuring in a long distance migrant shorebird, the dunlin (Calidris alpina). Proc Natl Acad Sci USA 90:94-98

Wenink PW, Baker AJ, Tilanus MGJ (1994) Mitochondrial controlregion sequences in two shorebird species, the turnstone and the dunlin, and their utility in population genetic studies. Mol Biol Evol 11:22-31

Wilson G, Rannala B (2003) Bayesian inference of recent migration rates using multilocus genotypes. Genetics 163:1177-1191 